\title{
EDITORIAL
}

\section{Life event stress and psychiatric illness ${ }^{1}$}

The idea that life stress can cause illness is supported more by faith than scientific evidence - so concluded Dohrenwend \& Dohrenwend (1978) in a recent review. In regard to physical illness Andrews \& Tennant (1978) have drawn attention to recent large-scale prospective studies which failed to find an association between life event stress and physical illness. Presumably the uniformly positive association between life stress and illness shown in retrospective studies must be due to problems in the recall of events by sick people. A life crisis, whether due to a single catastrophe or a surfeit of ordinary life events, may produce demoralization and dependence on medical services but has not been shown to cause the onset of physical disease. In animals, environmental stimuli that produce prolonged arousal and changes in hormonal and immune competence levels have resulted in physical illness. These mechanisms exist in humans but the human ability to recruit social support, defend intrapsychically and cope environmentally may limit arousal to non-pathogenic levels.

In psychiatry the picture is more complicated. Studies of disasters show that when the psychological stress is sufficiently severe, virtually everybody decompensates and becomes demoralized, dependent and identifiable as a psychiatric casualty. Such disasters are rare and the more relevant issue is whether the trials and tribulations of everyday life contribute to psychiatric illness. Belief in such an association is ubiquitous: but the problems in demonstrating predictive associations are legion. Five years ago it appeared from the pages of this Journal (Brown et al. 1973a, b; Jacobs et al. 1974) and from other publications (Brown, $1974 a, b$; Paykel, 1974) that 2 independent groups of investigators had succeeded in this task.

Which life events are to be regarded as stressful? In London Brown's group identified as events changes in life circumstances occurring to the subject; and role and health changes occurring to the subject, his relatives and household members. Events were carefully dated, the context or circumstances surrounding the event noted and event occurrence verified by interviewing relatives. The research team, taking the patient's individual circumstances into account but not his own reaction to the event, then made judgements as to the threat such an event would pose to the average person. In this way Brown hoped to reduce the principal bias confounding retrospective studies, the 'effort after meaning' as patients sought reasons to explain their illness. Given that the identification and scaling of such events could be reliably achieved, then the Brown technique had the potential advantage of being able to accommodate the infinite combinations of event and circumstance that constitute the predicaments of human existence.

An apparently more limited methodology was developed by the New Haven group (Paykel, 1974). They used a check list of some 60 items to ascertain events occurring in the 6 months prior to illness. Events were then analysed by area of activity (changes in health, work, family, etc.), by whether they represented entrances or exits to the person's social field, and by whether they were events of a socially desirable or undesirable nature. For some studies the events were weighted as to 'how upsetting the event would be to the average person' and the weighted scores of events experienced were summed to give an estimate of the life event stress impinging on an individual.

Despite the methodological differences the findings of the 2 groups are remarkably similar.

1 Address for correspondence: Dr J. G. Andrews, Urban Psychiatry Research Group, Prince Henry Hospital, Little Bay. NSW, Australia 2036. 


\section{SCHIZOPHRENIA}

Brown et al. $(1973 a, b)$ reported a study of 50 schizophrenic patients and compared their life event history to a sample of the local work-force similar in age, sex and area of residence. In the 3 months prior to onset of illness schizophrenics experienced more life events than did controls and 'the entire difference appeared to occur in the three week period immediately before onset . . . outside these three weeks the rate was much the same in the two groups' (Brown, 1974a). Brown concluded that a wide variety of events appeared capable of provoking an acute schizophrenic attack, whether it be the first or subsequent breakdown. The relationship held when only events independent of the patient's behaviour were included and held when events of differing degrees of threat were considered.

In the case of schizophrenia, the New Haven group has also generated data similar to that of Brown. Jacobs \& Myers (1976) found that 62 first episode schizophrenics reported $50 \%$ more life events over the preceding year than did controls matched from a community survey. The differences were considered to be consistent with a precipitant or triggering effect. Schizophrenics reported more undesirable and upsetting events, more events involving family, housing or legal disturbances. However, the authors expressed reservations about their data for when events possibly influenced by the subject's own behaviour were excluded, the difference disappeared.

\section{DEPRESSION}

Brown et al. (1973a) examined a mixed group of depressed female patients, 50 neurotic depressives and 64 endogenous depressives. Their life event histories were compared with those of a community sample of women free of psychiatric disorder. In the 9 months before onset the depressive women experienced a four-fold excess of markedly threatening events. Furthermore, in the 3 weeks prior to onset there was a heavy concentration of both markedly and moderately threatening events. Apart from this period, moderate and minor events occurred equally in both groups. Brown concluded that markedly threatening events could well play a part in the long-term development, as well as in the precipitation, of depressive breakdown.

Paykel et al. (1969) matched 185 depressed patients on sociodemographic variables with subjects from the community. In the 6 months prior to onset the depressed subjects reported 3 times as many events as did the control subjects. This relationship held for all categories of events. When events were dichotomized, depressives reported 5 times as many exits from their social field, more undesirable events, yet experienced the same number of entrance and desirable events as did the control subjects. Paykel (1974), attempting to evaluate the importance of recent loss in the genesis of depression, calculated that some $8 \%$ of depressions could be attributed to such exit events. Neither Paykel (1974) nor Brown et al. (1977) found the relation between life event stress and illness to be stronger for neurotic depression than for psychotic or endogenous depression.

\section{NEUROSIS}

Cooper \& Sylph (1973) studied new episodes of neurotic illness presenting in general practice, and employed Brown's technique to assess life events. They matched 34 neurotic patients and 34 nonneurotic patients on demographic variables. In the 3 months prior to onset neurotics reported twice as many events as did the control subjects, a significant difference. Cooper \& Sylph concluded that major life events play a significant role in the causation of neurotic illness.

Myers et al. (1971, 1972) conducted a survey of life events and psychological impairment (essentially the presence of neurotic symptoms but not necessarily of illness) in a community sample of 938 adults. They found a Pearson correlation of 0.34 between the measures. This relation held when events were divided by area of social activity - family, health, work, legal, etc. - and was independent of age, sex, social class and race of respondent. When events were categorized as exit or entrance events, or as desirable or undesirable events, then psychological impairment was best predicted by an excess of exit events on the one hand, and of undesirable events on the other. 
Two years later they studied the sample again. Persons experiencing an increase in symptoms reported an increase in life events over the period, persons reporting fewer life events complained of fewer symptoms. Regrettably the opportunity for a prospective study was not taken, and even with this 2-stage retrospective study it is possible that persons experiencing a worsening of their mental health would, in an 'effort after meaning', falsely recall events as having occurred in the period under study.

\section{IMPORTANCE OF FINDINGS}

The London group have developed a method of quantifying the threat of life events to the individual and have obtained positive, and claimed causal, associations with the main psychiatric disorders. Brown et al. $(1973 a, b)$ argued that in predisposed persons, life event stress brought forward in time illness to which the person would have eventually succumbed. The brought forward time was calculated as 3 years in neurosis, 2 years in depression and 10 weeks in schizophrenia. Recent life events were held to have a major aetiological role in neuroses presenting in general practice, a formative role in the occurrence of a mixed group of depressive illnesses, and a precipitant role in triggering schizophrenic episodes. The results of the New Haven Group are similar, and Paykel's (1974) calculation of brought forward time for depression was also 2 years. Paykel (1978) has argued that the relative risk is a better measure of the magnitude of the causative effect of life event stress. He calculated that, in the 6 months after an event, the risks of illness are increased between 2 and 7 times depending on the severity of the event and the type of illness; the risks are greatest for attempted suicide, less for neuroses and depression, and least for schizophrenia.

The size of the association between life events and depression or schizophrenia is small, accounting for less than $10 \%$ of the variance and is unlikely to have clinical or preventive importance. In the case of neurotic illness life events may be more important, but in this condition it is often difficult to date the onset, and early symptoms of illness may contribute to the occurrence of events. There is a prospective study of life events and psychiatric illness capable of resolving this problem. Theorell et al. (1975) studied 3000 middle-aged manual workers. After those with recent psychiatric illness were rejected, the remainder completed life event inventories for the previous year and then were followed for a further year. Elevated life event scores were significantly associated $(P<0.05)$ with the onset of neurotic illness causing greater than 30 days' incapacity. Given the large sample size and the smallness of the effect obtained, it does not seem that in this study life events were a major determinant of severe neurotic illness.

\section{WHAT DO LIFE EVENTS CAUSE?}

Having symptoms, being ill and being a patient are not necessarily the same thing, yet all 3 have been used interchangeably as the dependent variable in life event studies. Uhlenhuth \& Paykel $(1973 a, b)$ examined the relation between life event stress and symptom patterns in 213 psychiatric patients and 160 relatives of patients. Symptom intensity as determined by the Hopkins Symptom Check List was predicted by life event distress score. Race, sex, age and social class, but not life event score, were the best predictors of the predominant neurotic reaction pattern shown by these subjects. It might be concluded from this and other laboratory evidence (Sipprelle et al. 1977) that, while life event stress may demoralize people so that they experience dysphoric affects, the pattern of their symptoms is generated by intrinsic personality and sociodemographic attributes.

Schwartz \& Myers $(1977 a, b)$ studied 132 post-hospitalized schizophrenics matched with 132 community subjects. The discharged schizophrenics reported more symptoms and more life events than did their community controls, but the correlation between events and symptoms was weaker in the patients than in the controls. The excess of events experienced by the schizophrenics was in the health, work, legal and community crisis categories. Relating life event stress to particular symptoms, Schwartz \& Myers found that life events were related to anxiety, depression and somatic concerns, but explained only $2 \%$ of the variance in schizophrenic symptom scores. As with the 
Uhlenhuth \& Paykel study of neurotics, life events were related to dysphoric affect, while natural history and sociodemographic variables predicted the specific symptoms of schizophrenia.

Even if life events were reliably demonstrated as likely to cause illness, it would be difficult to think of prevention strategies. There has therefore been some real interest in looking for factors which may mediate between life event stress and illness. Brown et al. (1975) analysed their community study of depressed women and suggested that the increased risk of 'caseness' in working-class women could be attributed to the interaction between events and 3 other vulnerability factors: loss of mother in childhood, 3 or more children under 14, and lack of intimate relation with husband. Current employment was also a protective factor independent of class. C. C. Tennant and P. Bebbington (personal communication) have reanalysed Brown's data and suggest that the effects of these other social stressors are additive and independent, not interactive.

In another community study Andrews et al. $(1978 a, b)$ concluded that the risk of 'caseness' in the general population was varied by a factor of 4 by the effect of life event stress, social support and maturity of coping style. The 2 additional factors did not work by moderating the impact of life events but were independent determinants of the 'caseness' risk. All 3 factors were more important among women than men and might explain the higher morbidity rates in women. Myers et al. (1975) analysed their community data further and noted a similar finding, that those with high social integration were often well despite the presence of life event stress while low integration often predicted the occurrence of symptoms in the absence of stress. Life event stress may be best regarded as but one of many social and environmental factors non-specifically related to formal psychiatric illness.

\section{CONCLUSION}

As in many fields of investigation in which the initial hope of discovering a remediable aetiological agent begins to fade, life event research is becoming preoccupied with questions of methodology.

Which events are properly the concern of life event research? Are distress and upset the best measures of threat? How can one estimate the degree to which events are self caused? Over what period of time do events constitute an active stress? How does one measure or control for the effect of mediating or other independent variables? How can we be sure that events and illness are not both influenced by a third unknown factor? Is it symptoms or illness or patienthood that is being measured as the dependent variable? These issues are discussed at length by Alarcón \& Covi (1972), Brown et al. (1973a), Brown (1974b), Wershow \& Reinhart (1974), Tennant \& Andrews (1978 $a, b)$, Dohrenwend \& Dohrenwend (1978) and Hurst et al. (1978). Persons planning life event research should familiarize themselves with these issues before conducting further studies which lack power to add materially to what is already known. In the meantime, clinicians should continue to help their patients cope with their life event stress and gentle enquirers will be wise to suspend judgement on the issues until more evidence is to hand.

GAVIN ANDREWS AND CHRISTOPHER TENNANT

\section{REFERENCES}

Alarcón, R. de \& Covi, L. (1972). The precipitating event in depression. Journal of Nervous and Mental Disease 155, 379-391.

Andrews, G. \& Tennant, C. (1978). Being upset and becoming ill: an appraisal of the relation between life events and physical illness. The Medical Journal of Australia 1, 324-327.

Andrews, G., Tennant, C., Hewson, C. \& Schonell, M. $(1978 a)$. The relation of social factors to physical and psychiatric illness. American Journal of Epidemiology (in the press).

Andrews, G., Tennant, C., Hewson, D. M. \& Vaillant, G. E. $(1978 b)$. Life event stress, social support, coping style and risk of psychological impairment. Journal of Nervous and Mental Disease 166, 307-316.

Brown, G. W. (1974a). Life events and the onset of depressive and schizophrenic conditions. In Life Stress and Psychiatric Illness (ed. E. K. Gunderson and R. H. Rahe), pp. 164188. Charles C. Thomas: Springfield, Ill.

Brown, G. W. $(1974 b)$. Meaning measurement and stress of life events. In Stressful Life Events (ed. B. S. Dohrenwend and B. P. Dohrenwend), pp. 215-243. John Wiley and Sons: New York.

Brown, G. W., Sklair, F., Harris, T. O. \& Birley, J. L. T. $(1973 a)$. Life events and psychiatric disorders. Part 1: 
Some methodological issues. Psychological Medicine 3 , 74-87.

Brown, G. W., Harris, T. O. \& Peto, J. (1973b). Life events and psychiatric disorders. Part 2: Nature of causal link. Psychological Medicine 3, 159-176.

Brown, G. W., Bhrolchain, M. N. \& Harris, T. (1975). Social class and psychiatric disturbance among women in an urban population. Sociology 9, 225-254.

Brown, G. W., Harris, T. \& Copeland, J. R. (1977). Depression and loss. British Journal of Psychiatry 130, 1-18.

Cooper, B. \& Sylph, J. (1973). Life events and the onset of neurotic illness: an investigation in general practice. Psychological Medicine 3, 421-435.

Dohrenwend, B. S. \& Dohrenwend, B. P. (1978). Some issues in research on stressful life events. Journal of Nervous and Mental Disease 166, 7-15.

Hurst, M. W., Jenkins, C. D. \& Rose, R. M. (1978). The assessment of life change stress: a comparative and methodological inquiry. Psychosomatic Medicine 40, 127-132.

Jacobs, S. C. \& Myers, J. (1976). Recent life events and acute schizophrenic psychosis: a controlled study. Journal of Nervous and Mental Disease 162, 75-87.

Jacobs, S. C., Prusoff, B. A. \& Paykel, E. S. (1974). Recent life events in schizophrenia and depression. Psychological Medicine 4, 444-453.

Myers, J. K., Lindenthal, J. J. \& Pepper, M. P. (1971). Life events and psychiatric impairment. Journal of Nervous and Mental Disease 153, 149-157.

Myers, J. K., Lindenthal, J. J. \& Pepper, M. P. (1972). Life events and mental status: a longitudinal study. Journal of Health and Social Behaviour 13, 398-406.

Myers, J. K., Lindenthal, J. J. \& Pepper, M. P. (1975). Life events, social integration and psychiatric symptomatology. Journal of Health and Social Behaviour 16, 421-427.

Paykel, E. S. (1974). Recent life events and clinical depression.
In Life Stress and Psychiatric Illness (ed. E. K. Gunderson and R. H. Rahe), pp. 134-163. Charles C. Thomas: Springfield, Ill.

Paykel, E. S. (1978). Contribution of life events to causation of psychiatric illness. Psychological Medicine 8, 245-253.

Paykel, E. S., Dienelt, M. N. \& Lindenthal, J. J. (1969). Life events and depression. Archives of General Psychiatry 21, $753-760$

Schwartz, C. C. \& Myers, J. K. (1977a). Life events and schizophrenia. Archives of General Psychiatry 34, 12381241.

Schwartz, C. C. \& Myers, J. K. (1977b). Life events and schizophrenia. Archives of General Psychiatry 34, 12421245.

Sipprelle, R. C., Ascough, J. C. \& Detrio, D. M. (1977). Neuroticism, extroversion, and response to stress. Behaviour Research and Therapy 15, 411-418.

Tennant, C. \& Andrews, G. (1978a). The cause of life event in neurosis. Journal of Psychosomatic Research 22, 41-45.

Tennant, C. \& Andrews, G. (1978 b). The pathogenic quality of life event stress in neurotic impairment. Archives of General Psychiatry (in the press).

Theorell, T., Lind, E. \& Floderus, B. (1975). The relationship of disturbing life changes and emotions to the early development of myocardial infarction and other serious illnesses. Journal of Epidemiology 4, 281-293.

Uhlenhuth, E. H. \& Paykel, E. S. (1973a). Symptom intensity and life events. Archives of General Psychiatry 28, 473-477.

Uhlenhuth, E. H. \& Paykel, E. S. $(1973 b)$. Symptom configuration and life events. Archives of General Psychiatry 28, 744-748.

Wershow, H. \& Reinhart, G. (1974). Life change and hospitalization - a heretical view. Journal of Psychosomatic Research 18, 393-401. 